\title{
Heart Rate Response and Match Repeated-Sprint Performance in Chinese Elite Youth Soccer Players 中國青年足球運動員比賽時的心率及重覆衝跑表現
}

\section{Del P. WONG ${ }^{1}$ Karim CHAMARI $^{2}$ Anis CHAOUACHI ${ }^{2}$ Tze Chung LUK ${ }^{3}$ Patrick Wing Chung LAU $^{3}$}

\author{
${ }^{I}$ Department of Health and Physical Education, \\ The Hong Kong Institute of Education, HONG KONG \\ ${ }^{2}$ Tunisian Research Laboratory "Sport Performance Optimisation" \\ National Center of Medicine \& Science in Sport, Tunis, TUNISIA \\ ${ }^{3}$ Department of Physical Education, \\ Hong Kong Baptist University, HONG KONG
}

\section{${\text { 王培林 }{ }^{1} \text { 卡裏姆 }^{2} \quad \text { 阿尼斯·沙瓦希 }}^{2}$ \\ 陸子聰 ${ }^{3} \quad$ 劉永松 $^{3}$}

${ }^{1}$ 香港教育學院健康與體育學系

2突尼西亞國家運動醫學與科學研究中心

3香港浸會大學體育學系

\begin{abstract}
The purpose of this study is to investigate the heart rate (HR) response and repeated-sprint performance throughout the match among Chinese elite youth soccer players. Two elite youth soccer teams each consisted of 11 players participated in the study. The HR measurement and repeated-sprint test were conducted (age: 17.1 \pm 0.85 , height: $173 \pm 5.2 \mathrm{~cm}$; weight: 64.2 $\pm 8.1 \mathrm{~kg}$ ). HR was recorded every $5 \mathrm{~s}$ throughout the match, while repeated-sprint consisted of three $30 \mathrm{~m}$ sprints separated by a $25 \mathrm{~s}$ active recovery period that was conducted: $5 \mathrm{~min}$ before the match (T1), $5 \mathrm{~min}$ before the end of the first half (T2), $5 \mathrm{~min}$ before the start of the second half (T3), and $5 \mathrm{~min}$ before the end of the second half (T4). HR was in the range of $160-169 \mathrm{bpm}$ for $25 \%$ of total play time, followed by $170-179 \mathrm{bpm}$ for $23.6 \%$. HR during the $46-60 \mathrm{~min}$ was significantly lower than other intervals $(\mathrm{P}<0.05)$, and repeated-sprint time at $\mathrm{T} 3$ was significantly slower than others. The intensity of the match was lower than those found in European players, indicating the cardiovascular fitness and repeated-sprint performance are needed among the players. High-intensity and low-volume interval training, and re-warm up before the start of second half are suggested in the training program.
\end{abstract}

Keywords: football, intensity, performance, Asia

\section{摘 要}

本研究旨在測定中國青年足球運動員比賽時的心率及重覆衝跑測試表現。對兩支分別由 11 人組成的足球隊運動員（年齡： $17 \pm 0.85$ 歲, 身高 : $173 \pm 5.2 \mathrm{~cm}$ 㾖米, 體重 $: 64.2 \pm 8.1$ 公斤) 進行了心率測量以及重覆衝跑測試。比賽時每 5 秒鐘記錄一 次心率。重覆衝跑測試由3次 30 米衝跑組成, 每次有25秒動態休息。重覆衝跑測試共進行四次, 分別在：賽前5分鐘（T1）, 中場 
前5分鐘(T2), 下半場開始前5分鐘( $\mathrm{T} 3$ )及比賽結束前5分鐘( $\mathrm{T} 4$ )進行。結果在 $25 \%$ 的比賽時間內, 運動員的心率在每分鐘 $160-169$ 之 間, 其次是 $23.6 \%$ 的時間內為每分鐘 170-179。在 46-60分鐘的比賽中, 運動員的心率顯著低於其他時段 $(\mathrm{P}<0.05)$, 而運動員在第三次 重覆衝跑測試時的速度顯著低於其他三次測試。本次研究結果顯示比賽強度低於歐洲青年足球員進行的同類測試, 説明中國青年 足球運動員需要加強心肺功能及提高重覆衝跑的表現。建議訓練時進行大強度低密度的間歇訓練, 及在比賽中場開始前再次進行 熱身。

關鍵字: 足球、強度、表現、亞洲

\section{Introduction}

Soccer is an intermittent sport in which elite-level players have to run about $10-12 \mathrm{~km}$ in a $90-\mathrm{min}$ match (Stolen, Chamari, Castagna, \& Wisloff, 2005). In addition, more than $90 \%$ of each soccer match is performed by aerobic metabolism (Bangsbo, 1994b), with average and peak heart rates around 85 and $98 \%$ of maximal values (Bangsbo, 1994b; M. Mohr, Krustrup, Nybo, Nielsen, \& Bangsbo, 2004). In general, the heart rate response for an European player during a soccer match has been reported to be between 150 and 175bpm (Ali \& Farrally, 1991; Bangsbo, 1994a, 1994b; Bangsbo, Norregaard, \& Thorso, 1991; Reilly, 1990, 1997, 1994; Van Gool, Van Gervan, \& Boutmans, 1988). Based on these findings of physiological load during the match, a lot of quantified training methods have been developed to optimize soccer players' performance (Dupont, Akakpo, \& Berthoin, 2004; Eniseler, 2005; Hoff, 2005; Hoff \& Helgerud, 2004; Hoff, Wisloff, Engen, Kemi, \& Helgerud, 2002; Impellizzeri et al., 2006; Krustrup, Mohr, Ellingsgaard, \& Bangsbo, 2005; McMillan, Helgerud, Macdonald, \& Hoff, 2005). However, although soccer is played in different styles throughout the world and in different age categories, there is no information available in the literature with regard to the heart rate response of Chinese elite youth soccer players during the match.

The characteristic of a soccer match has been reported by Douglas (1993) showing a reduction in distance covered, lower play intensity, reduced heart rate, reduced blood sugar levels, and reduced lactate levels in the second half of match compared with the first half. Specifically, it has been reported that European top-class professional players perform less high-intensity running in the second half compared with the first half of a match (Magni Mohr, Krustrup, \& Bangsbo, 2003). Some studies also reported that the ability to perform high-intensity exercise (i.e. repeated-sprint) is reduced towards the end of elite as well as sub-elite soccer matches, indicating that players experience fatigue towards the end of the match (M. Mohr, et al., 2004; Magni Mohr, et al., 2003). Similar study on repeated-sprint performance has not been conducted on Chinese elite youth soccer players and therefore no information is available if such decline of high-intensity performance exists in Chinese elite youth soccer players.

In recent years, there has been a rapid growth of soccer standards in Asia, which is demonstrated by the general increase in the world ranking of Asian countries between 2001 - 2006: Japan (from 40 to 15), Korea Republic (from 42 to 29), Saudi Arabia (from 38 to 33), China (from 76 to 73), and Hong Kong (from 123 to 117) (FIFA, 2006). In 2002, Korea Republic ranked third runner-up in the FIFA World Cup. However, studies on Asian players are limited, and the general practice among Asian countries is to adopt the findings from studies based on foreign players. However, it has been recently shown that the physical characteristics of national players from various confederations are very different (Wong et al., 2008), with Asian players being less body weight and shorter body height compared to those players from Africa and Europe. These physical differences may impose different physiological loading on Asian soccer players. Therefore, it may not be appropriate to use the findings of the abovementioned studies based on European players, and further apply on Asian players without knowing the physiological loading they actually experienced during the match.

Therefore the primary purpose of this study was to investigate the HR response among Chinese elite youth soccer players during the match. The secondary purpose was to examine if the high-intensity performance (i.e. repeated-sprint) vary throughout the match among these players. The results of this study would provide evidence for strength and conditioning coach to tailor-made specific training program to the needs of Asian soccer players; and for manager/coach to design match tactics based on the fitness outcome of their players. 


\section{Methods}

\section{Subjects}

Two Chinese elite youth soccer teams each consisted of 11 players participated in the study. These players were competing in the youth league and had one official match per week. Goalkeepers from both teams were involved in the match but no heart rate measurement was recorded. Therefore, the heart rate measurement and repeated-sprint test were conducted on 20 players (age: 17.1 \pm 0.85 , height: $173 \pm 5.2 \mathrm{~cm}$; weight: $64.2 \pm 8.1 \mathrm{~kg}$ ). All of them were informed about the experimental procedure, potential risks and rights to terminate the experiment at any time. They signed a written consent before participation. The protocol was approved by the clinical research ethics committee.

\section{Study Design}

Since the heart rate transmitter belt is not permitted during official matches, the data of this study were collected during a 90min friendly match. The studied friendly match was scheduled in the competitive season 3 days after an official match. HR monitor (Polar, Kempele, Finland) with weight of $\sim 100 \mathrm{~g}$ was worn by each of the 20 players prior to any exercise. Players then carried out the same warm up routines as they do before the official match: 30min warm up at the intensity of HR $\sim 135 \mathrm{bpm}$, which included static and dynamic stretching, several acceleration and sprints, and small-sided 5 vs 5 ball possession for approximately $5 \mathrm{~min}$. No specific tactical instruction was provided by the coaches to increase/ decrease play intensity throughout the match. HR was recorded every $5 \mathrm{~s}$ throughout the match, and HR during the first and second halves were analyzed.

The repeated-sprint test was previously described by Mohr et al (2004). Briefly, the repeated-sprint test was conducted: $5 \mathrm{~min}$ before the match (T1), $5 \mathrm{~min}$ before the end of the first half (T2), $5 \mathrm{~min}$ before the start of the second half (T3), and $5 \mathrm{~min}$ before the end of the second half (T4). To determine the sprint time, player was taken out of the match for approximately $1.5 \mathrm{~min}$ and replaced by a substitute player to maintain the 11 vs 11 match. The repeated-sprint test consisted of three $30 \mathrm{~m}$ sprints separated by a $25 \mathrm{~s}$ active recovery period during which the players jogged back to the start line. The sprint started with a standing position and sprint time was recorded by infrared timing sensors having a precision of $0.01 \mathrm{~s}$
(Speedtrap II Wireless Timing System, Brower Timing System, Australia), which located at the starting line $(0 \mathrm{~m})$ and the finishing line $(30 \mathrm{~m})$ at $1 \mathrm{~m}$ height. The average of each three $30 \mathrm{~m}$ repeated-sprint was analyzed.

\section{Statistical Analysis}

Repeated measures one-way ANOVA with alpha value set at 0.05 was employed to examine: a) the difference of heart rate between the 6 time match intervals with each consisting of $15 \mathrm{~min}$; and b) the difference of repeatedsprint time between the 4 measurements (T1, T2, T3, and T4). Pairwise comparison with Bonferroni adjustment was employed to keep the experiment-wise error rate at 0.05 (Bland \& Altman, 1995). Values are presented as mean \pm standard deviation.

\section{Results}

Results show that during the match, HR was in the range of $160-169 \mathrm{bpm}$ for $25 \%$ of total play time, followed by $170-179 \mathrm{bpm}$ for $23.6 \%$ of total play time, and $150-159 \mathrm{bpm}$ for $19.2 \%$ of total play time (Figure 1). Significant differences of HR between the 6 time intervals $(\mathrm{F}=40.07, \mathrm{p}<0.01)$ (Figure 2), and repeated sprint time between $\mathrm{T} 1 \quad(4.22 \pm 0.11), \mathrm{T} 2 \quad(4.27 \pm 0.11), \mathrm{T} 3$ $(4.36 \pm 0.17)$, and $\mathrm{T} 4(4.31 \pm 0.14)(\mathrm{F}=15.18, \mathrm{p}<0.01)$ (Figure 3) were observed.

\section{Discussion}

\section{Heart Rate Response during Match}

HR was in the range of $160-169 \mathrm{bpm}$ for $25 \%$, and $170-179 \mathrm{bpm}$ for $23.6 \%$ of total play time (Figure 1). Thus $\sim 50 \%$ of the studied match was at the intensity equivalent to players' $\sim 80 \%$ - $90 \%$ age-predicted maximal HR. The intensity of the match was lower than those found in European players (85\%-98\%) (Bangsbo, 1994b; M. Mohr, et al., 2004; Stolen, et al., 2005). Furthermore, it has been recently reported that based on the proper allometric scaling (Chamari, Moussa-Chamari, et al., 2005), the VO2max of Chinese elite youth soccer players $(170 \mathrm{ml} / \mathrm{kg} 0.75 / \mathrm{min})$ is lowered than those of elite youth soccer players from Scotland $(183 \mathrm{ml} / \mathrm{kg} 0.75 / \mathrm{min})$ and Tunisia (177 $\mathrm{ml} / \mathrm{kg} 0.75 / \mathrm{min}$ ) (Wong \& Wong, in press). The lower VO2max value together with the lower intensity of match both urge for the needs of appropriate fitness training among the Chinese elite youth soccer players. The results of this study provide evidence for 
cardiovascular training at the specific intensity $(\mathrm{HR}=160$ $179 \mathrm{bpm}$, or $80-90 \%$ of maximal HR) to optimize players' running ability. Indeed, it has been reported that improved VO2max would improve players' field performance, such as increased distance coverage, more involvement with the ball, increased number of sprints, and similar technical performance despite significantly higher exercise intensity through higher HR (Helgerud, Engen, Wisloff, \& Hoff, 2001). In order to improve players' cardiovascular level within the limited training time, strength and conditioning coach may adopt interval training instead of the traditional continuous training. Since it has been recently shown that high-intensity and low-volume interval training yield similar effect in carotid and popliteal artery distensibilities (Rakobowchuk et al., In press), muscle oxidative capacity, muscle glycogen content (Gibala et al., 2006), muscle carbohydrate (Burgomaster et al., 2008), compared to highvolume endurance training. These results demonstrated that high-intensity and low-volume interval training is a timeefficient strategy to induce rapid improvement in skeletal muscle and exercise performance that are comparable to traditional endurance training. Alternatively, strength and conditioning coach can implement soccer-specific dribbling interval training (Hoff, et al., 2002) to simultaneously develop players' cardiovascular fitness and soccer skill. It has been shown that by performing this soccer-specific interval of 4 set $x$ 4min (intensity $\sim 90-95 \%$ of player's maximal HR), with a 3 min recovery jog at $70 \%$ of player's maximal HR in-between set, twice per week for 10 weeks improved elite youth players' VO2max of $10 \%$ (Chamari, Hachana, et al., 2005; McMillan, et al., 2005).

The lowest average HR was found at the intervals of 46-60min and 76-90min (Figure 2). The decreased match intensity at $46-60 \mathrm{~min}$ might be the result of lower muscle temperature after the $15 \mathrm{~min}$ rest betweenhalves. As previously reported by Mohr et al (2004) that muscle temperature at the beginning of second half is significantly lower than the average value of the first half (37.8 vs 39.5 oC). The decreased intensity at 7690 min might be the results of lower muscle ATP, CP, and glycogen levels, together with an increase in muscle lactate concentration towards the end of the match (Krustrup et al., 2006).

Figure 1. Heart rate frequency distributions during the match among all players $(\mathrm{n}=20)$.

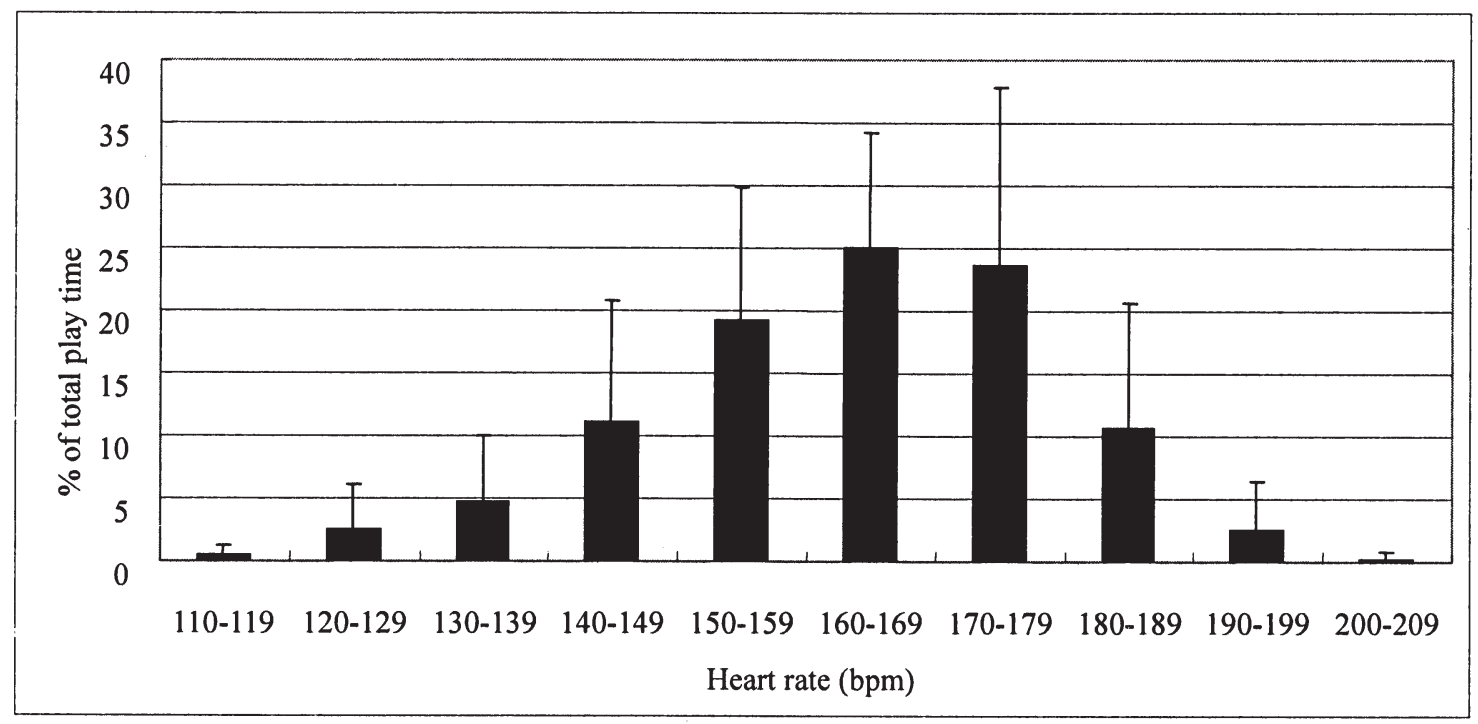


Figure 2. Average heart rate of all players $(n=20)$ during the match with play time divided into 6 intervals. ** Significant differences exist in all cases showed in brackets $(p<0.01)$.

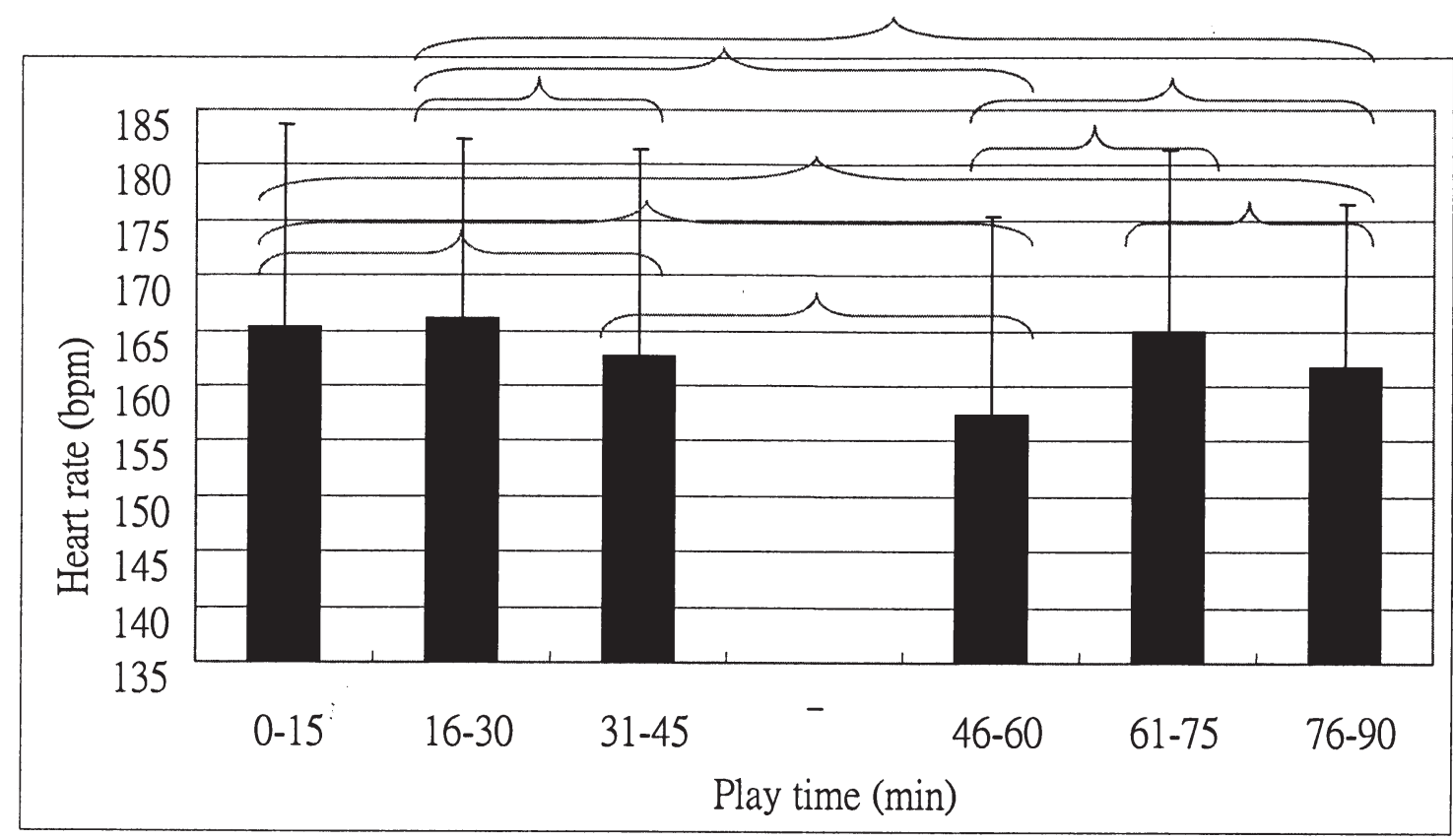

\section{Repeated-Sprint Performance}

Although aerobic metabolism dominates the energy delivery during a soccer match, the most decisive action is explosive and therefore is anaerobic (Stolen, et al., 2005). In addition, it has been shown that top-class soccer players perform significantly more sprints during the match than the players at lower standard (Ekblom, 1986; Magni Mohr, et al., 2003). In this study, the repeated sprint performance deteriorated throughout the match (Figure 3), meaning that the players were incapable to maintain their initial speed of repeated-sprint, which is important in soccer. This is in agreement with Rebelo et al. (1998) that soccer players had a reduced ability to perform repeated-sprints after the match compared to that before the match. Therefore, they further indicated that fatigue had developed before the end of a soccer match. Another previous study (Krustrup, et al., 2006) investigated the muscle and blood metabolites found that the values of muscle ATP (23 vs $26.4 \mathrm{mmol} / \mathrm{kg}$ d.w.), CP (79 vs $88 \mathrm{mmol} / \mathrm{kg}$ d.w.), and glycogen (255 vs $449 \mathrm{mmol} / \mathrm{kg}$ d.w.) were significantly lower after the match, compared to prematch, respectively. On the other hand, muscle lactate was significantly higher after that match (13 vs $4.2 \mathrm{mmol} / \mathrm{kg}$ d.w.) compared to that before match.
In addition, the repeated-sprint performance was significantly slower at $\mathrm{T} 3$, which also has been observed by Mohr et al (2004) in Danish forth division soccer players. They reported that the muscle temperature of players at the beginning of second half $\left(\sim 37.5^{\circ} \mathrm{C}\right)$ was lower than that at the end of first half $\left(\sim 39.5^{\circ} \mathrm{C}\right)$. They also reported that decrease in muscle temperature was correlated to the reduction in sprint performance $(r=0.60$, $\mathrm{P}<0.05$ ), and sprint performance was reduced by $1.2 \%$ per ${ }^{\circ} \mathrm{C}$. Therefore, they concluded that lower muscle temperature is one of the main reasons for poor repeated-sprint performance just before the beginning of the second half.

The practical implication of the results of repeatedsprint performance from this study were: (1) strength and conditioning coach has to design procedures to improve players' repeated-sprint performance at the beginning of second half, such as re-warm up before the start of second half to bring up the muscle temperature (M. Mohr, et al., 2004), or proper intake of food/ drink to restore hydration (Rico-Sanz et al., 1996), muscle glycogen levels (Kirkendall, 1993), and creatine (Mujika, Padilla, Ibanez, Izquierdo, \& Gorostiaga, 2000); (2) strength and conditioning coach has to target their training so that the effect of fatigue towards the end of the match is minimized or delayed; and (3) manager/ 
coach has to design appropriate tactic to avoid conceding goals, especially at the beginning of the second half when the ability to repeat sprints is temporary decreased. In addition, the team with better tactical ability can control the pace of the match so that the performance capabilities of players are not overtaxed (Reilly, 1997). Alternatively, players may share the high-intensity activity (sprint) in turn so that the overall pace of match is maintained, but the high-intensity works of each individual player is reduced.

Figure 3. Comparison of average repeated sprint time performed at 4 time intervals (T1, T2, T3, and T4). * $\mathrm{p}<0.05 ; * * \mathrm{p}<0.01$.

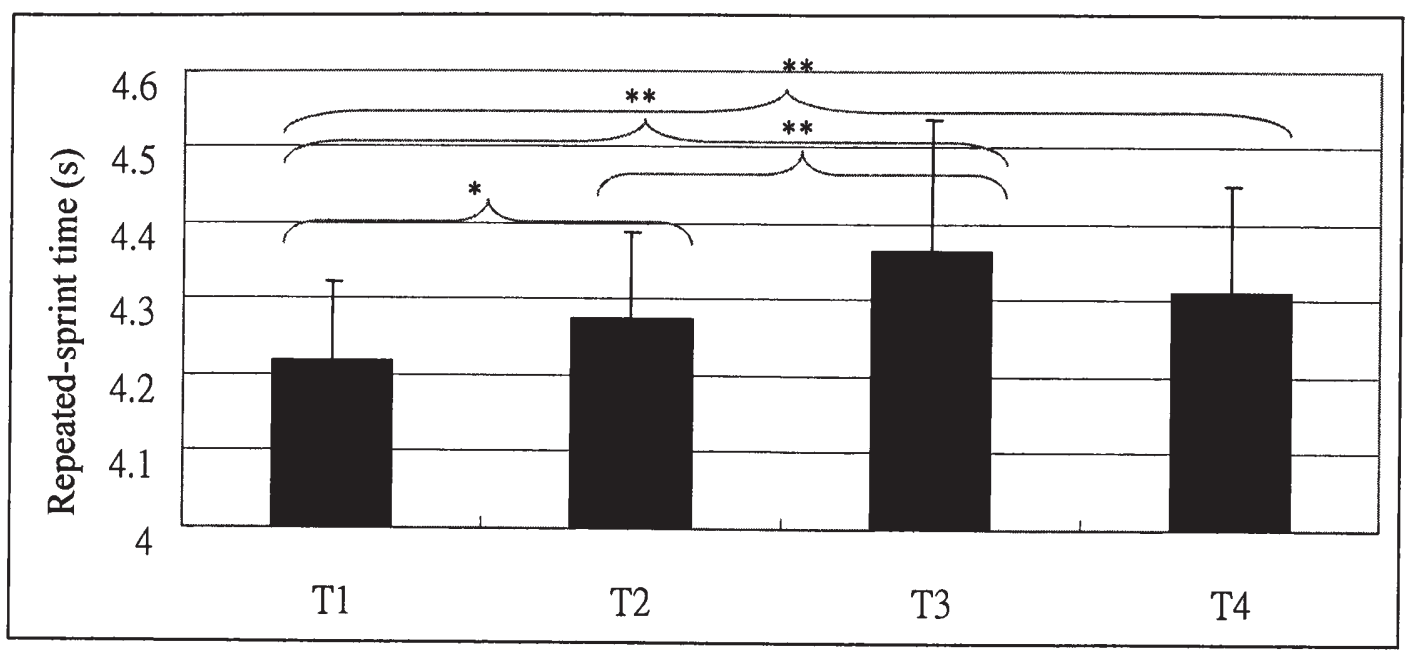

\section{Conclusion}

In the studied match of this study, heart rate was in the range of $160-169 \mathrm{bpm}$ for $25 \%$, and $170-179 \mathrm{bpm}$ for $23.6 \%$ of total play time (Figure 1). Thus $\sim 50 \%$ of the studied match was at the intensity equivalent to players' $\sim 80 \%$ - $90 \%$ of maximal heart rate. This match intensity is lower than that found in European players. The lowest average heart rate was found at the intervals of 46$60 \mathrm{~min}$ and $76-90 \mathrm{~min}$, and the repeated-sprint performance was significantly slower at the beginning of the second half. Therefore, we suggest strength and conditioning coach to design procedures to improve players' repeatedsprint performance at the beginning of second half, such as re-warm up before the start of second half, or proper intake of food/drink to restore hydration, muscle glycogen levels and creatine. In addition, manager/coach has to design the tactic especially at the beginning of the second half to avoid conceding goals. In order to improve players' cardiovascular level within the limited training time, strength and conditioning coach may adopt interval training instead of the traditional continuous training.

\section{References}

Ali, A., \& Farrally, M. (1991). Recording soccer players' heart rates during matches. Journal of Sports Sciences, 9(2), 183-189.

Bangsbo, J. (1994a). Physiological demands. In B. Ekblom (Ed.), Handbook of sports medicine and science: Football (soccer) (pp. 43-59). Oxford, UK: Blackwell Scientific Publications.

Bangsbo, J. (1994b). The physiology of soccer--with special reference to intense intermittent exercise. Acta Physiologica Scandinavica Supplementum, 619, 1-155.

Bangsbo, J., Norregaard, L., \& Thorso, F. (1991). Activity profile of competition soccer. Canadian Journal of Sport Sciences, 16(2), 110-116.

Bland, J. M., \& Altman, D. G. (1995). Multiple significance tests: The Bonferroni method. BMJ 310, 170. 
Burgomaster, K. A., Howarth, K. R., Phillips, S. M., Rakobowchuk, M., MacDonald, M. J., McGee, S. L., \& Gibala, M. J. (2008). Similar metabolic adaptations during exercise after low volume sprint interval and traditional endurance training in humans. Journal of Physiology-London, 586(1), 151-160.

Chamari, K., Hachana, Y., Kaouech, F., Jeddi, R., MoussaChamari, I., \& Wisloff, U. (2005). Endurance training and testing with the ball in young elite soccer players. British Journal of Sports Medicine, 39(1), 24-28.

Chamari, K., Moussa-Chamari, I., Boussaidi, L., Hachana, Y., Kaouech, F., \& Wisloff, U. (2005). Appropriate interpretation of aerobic capacity: allometric scaling in adult and young soccer players. British Journal of Sports Medicine, 39(2), 97-101.

Douglas, T. (1993). Physiological characteristics of elite soccer players. Sports Medicine, 16, 80-96.

Dupont, G., Akakpo, K., \& Berthoin, S. (2004). The effect of in-season, high-intensity interval training in soccer players. Journal of Strength \& Conditioning Research, 18(3), 584-589.

Ekblom, Bjorn. (1986). Applied Physiology of Soccer. 3, p. $50-60$.

Eniseler, N. (2005). Heart rate and blood lactate concentrations as predictors of physiological load on elite soccer players during various soccer training activities. Journal of Strength \& Conditioning Research, 19(4), 799-804.

FIFA. (2006). FIFA World Ranking.

Gibala, M. J., Little, J. P., van Essen, M., Wilkin, G. P., Burgomaster, K. A., Safdar, A., \& Tarnopolsky, M. A. (2006). Short-term sprint interval versus traditional endurance training: similar initial adaptations in human skeletal muscle and exercise performance. Journal of Physiology-London, 575(3), 901-911.
Helgerud, J., Engen, L. C., Wisloff, U., \& Hoff, J. (2001). Aerobic endurance training improves soccer performance. Medicine And Science In Sports And Exercise, 33(11), 1925-1931.

Hoff, J. (2005). Training and testing physical capacities for elite soccer players. Journal of Sports Sciences, 23(6), 573-582.

Hoff, J., \& Helgerud, J. (2004). Endurance and strength training for soccer players: physiological considerations. Sports Medicine, 34(3), 165-180.

Hoff, J., Wisloff, U., Engen, L. C., Kemi, O. J., \& Helgerud, J. (2002). Soccer specific aerobic endurance training. British Journal of Sports Medicine, 36(3), 218-221.

Impellizzeri, F. M., Marcora, S. M., Castagna, C., Reilly, T., Sassi, A., Iaia, F. M., \& Rampinini, E. (2006). Physiological and performance effects of generic versus specific aerobic training in soccer players. International Journal of Sports Medicine, 27(6), 483492.

Kirkendall, D. T. (1993). Effects Of Nutrition On Performance In Soccer. Medicine And Science In Sports And Exercise, 25(12), 1370-1374.

Krustrup, P., Mohr, M., Ellingsgaard, H., \& Bangsbo, J. (2005). Physical demands during an elite female soccer game: importance of training status. Medicine \& Science in Sports \& Exercise, 37(7), 1242-1248.

Krustrup, P., Mohr, M., Steensberg, A., Bencke, J., Kjer, M., \& Bangsbo, J. (2006). Muscle and blood metabolites during a soccer game: implications for sprint performance. Medicine and Science in Sports and Exercises, 38(6), 1165-1174.

McMillan, K., Helgerud, J., Macdonald, R., \& Hoff, J. (2005). Physiological adaptations to soccer specific endurance training in professional youth soccer players. British Journal of Sports Medicine, 39(5), 273-277. 
Mohr, M., Krustrup, P., Nybo, L., Nielsen, J. J., \& Bangsbo, J. (2004). Muscle temperature and sprint performance during soccer matches--beneficial effect of re-warm-up at half-time. Scandinavian Journal of Medicine \& Science in Sports, 14(3), 156-162.

Mohr, M., Krustrup, P., \& Bangsbo, J. (2003). Match Performance of high-standard soccer players with special reference to development of fatigue. Journal of Sports Sciences, 21, 519-528.

Mujika, I., Padilla, S., Ibanez, J., Izquierdo, M., \& Gorostiaga, E. (2000). Creatine supplementation and sprint performance in soccer players. Medicine \& Science in Sports \& Exercise, 32(2), 518-525.

Rakobowchuk, M., Tanguay, S., Burgomaster, K.A., Howarth, K.R., Gibala, M.J., \& Macdonald, M.J. (In press). Sprint interval and traditional endurance training induce similar improvements in peripheral arterial stiffness and flow mediated dilation in healthy humans. Am J Physiol Regul Integr Comp Physiol.

Rebelo, N., Krustrup, P., Soares, J., \& Bangsbo, J. (1998). Reduction in intermittent exercise performance during a soccer match. Journal of Sports Sciences, 16, 482483.

Reilly, T. (1990). Football. In T. Reilly, N. Secher, P. Snell \& C. Williams (Eds.), Physiology of Sports (pp. 371-425). London: E. \& F. N. Spon.

Reilly, T. (1997). Energetics of high-intensity exercise (soccer) with particular reference to fatigue. Journal of Sports Sciences, 15(3), 257-263.
Reilly, T. (Ed.). (1994). Physiological profile of the player. Oxford: Blackwell Scientific.

Rico-Sanz, J., Frontera, W. R., Rivera, M. A., Rivera-Brown, A., Mole, P. A., \& Meredith, C. N. (1996). Effects of hyperhydration on total body water, temperature regulation and performance of elite young soccer players in a warm climate. International Journal of Sports Medicine, 17(2), 85-91.

Stolen, T., Chamari, K., Castagna, C., \& Wisloff, U. (2005). Physiology of soccer: an update. Sports Medicine, 35(6), 501-536.

Van Gool, D., Van Gervan, D., \& Boutmans, J. (Eds.). (1988). The physiological load imposed on soccer players during real match-play. London: E \& FN Spon.

Wong, P., Mujika, I., Castagna, C., Chamari, K., Lau, P.W.C., \& Wisloff, U. (2008). Characteristics of World Cup Soccer Players. Soccer Journal(Jan-Feb), 57-62.

Wong, P., \& Wong, S. (in press). Physiological profile of Asian elite youth soccer players. Journal of Strength and Conditioning Research.

\section{Correspondence}

Dr Patrick Lau

Department of Physical Education, Hong Kong Baptist University, Kowloon Tong, Hong Kong.

Email: wclau@hkbu.edu.hk 